\title{
Activation of the transcription factor carbohydrate-responsive element-binding protein by glucose leads to increased pancreatic beta cell differentiation in rats
}

\author{
A. Soggia • K. Flosseau • P. Ravassard • G. Szinnai • \\ R. Scharfmann • G. Guillemain
}

Received: 10 January 2012 / Accepted: 17 May 2012 /Published online: 5 July 2012

(C) The Author(s) 2012. This article is published with open access at Springerlink.com

\begin{abstract}
Aims/hypothesis Pancreatic cell development is a tightly controlled process. Although information is available regarding the mesodermal signals that control pancreatic development, little is known about the role of environmental factors such as nutrients, including glucose, on pancreatic development. We previously showed that glucose and its metabolism through the hexosamine biosynthesis pathway (HBP) promote pancreatic endocrine cell differentiation. Here, we analysed the role of the transcription factor carbohydrate-responsive elementbinding protein (ChREBP) in this process. This transcription factor is activated by glucose, and has been recently described as a target of the HBP.

Methods We used an in vitro bioassay in which pancreatic endocrine and exocrine cells develop from rat embryonic pancreas in a way that mimics in vivo pancreatic development. Using this model, gain-of-function and loss-offunction experiments were undertaken.

Results ChREBP was produced in the endocrine lineage during pancreatic development, its abundance increasing with
\end{abstract}

Electronic supplementary material The online version of this article (doi:10.1007/s00125-012-2623-0) contains peer-reviewed but unedited supplementary material, which is available to authorised users.

A. Soggia $\cdot$ K. Flosseau $\cdot$ R. Scharfmann $\cdot$ G. Guillemain $(\bowtie)$

INSERM U845, Research Center Growth and Signalling,

Université Paris Descartes, Sorbonne Paris Cité,

Faculté de Médecine, Hôpital Necker,

Paris, France

e-mail: ghislaine.guillemain@inserm.fr

P. Ravassard

CNRS - UMR 7225, CNRS - UMR 7225 Hôpital Pitié

Salpêtrière,

Paris, France

G. Szinnai

Department of Biomedicine, University of Basel,

Basel, Switzerland differentiation. When rat embryonic pancreases were cultured in the presence of glucose or xylitol, the production of ChREBP targets was induced. Concomitantly, beta cell differentiation was enhanced. On the other hand, when embryonic pancreases were cultured with inhibitors decreasing ChREBP activity or an adenovirus producing a dominantnegative ChREBP, beta cell differentiation was reduced, indicating that ChREBP activity was necessary for proper beta cell differentiation. Interestingly, adenovirus producing a dominant-negative ChREBP also reduced the positive effect of $N$-acetylglucosamine, a substrate of the HBP acting on beta cell differentiation.

Conclusions/interpretation Our work supports the idea that glucose, through the transcription factor ChREBP, controls beta cell differentiation from pancreatic progenitors.

Keywords Carbohydrate-responsive element-binding protein · Glucose metabolism · Insulin · Pancreatic beta cell differentiation $\cdot$ Pancreatic development $\cdot$ Pentose phosphate pathway

\begin{tabular}{|c|c|}
\hline \multicolumn{2}{|c|}{ Abbreviations } \\
\hline ACCase & Acetyl-CoA carboxylase \\
\hline ChREBP & $\begin{array}{l}\text { Carbohydrate-responsive element-binding } \\
\text { protein }\end{array}$ \\
\hline dnChREBP & $\begin{array}{l}\text { Dominant-negative carbohydrate-responsive } \\
\text { element-binding protein }\end{array}$ \\
\hline FAS & Fatty acid synthase \\
\hline GFP & Green fluorescent protein \\
\hline GlcNAc & $N$-Acetylglucosamine \\
\hline HBP & Hexosamine biosynthetic pathway \\
\hline L-PK & Liver-type pyruvate kinase \\
\hline NEUROG3 & Neurogenin 3 \\
\hline $\mathrm{PC} 1 / 3$ & Proconvertase $1 / 3$ \\
\hline PDX1 & Pancreatic and duodenum homeobox 1 \\
\hline PP2A & Protein phosphatase $2 \mathrm{~A}$ \\
\hline
\end{tabular}




\section{Introduction}

The mature pancreas contains exocrine acinar cells that secrete digestive enzymes into the intestine, and endocrine islets that synthesise hormones such as insulin (beta cells), glucagon (alpha cells), somatostatin (delta cells) and pancreatic polypeptide (PP cells). The pancreas originates from the dorsal and ventral regions of the foregut endoderm directly posterior to the stomach. The first indication of pancreatic morphogenesis occurs in mice at embryonic day (E) 8.5 (E9.5 in rat), when the endoderm evaginates to form buds. Subsequently, the mesenchyme condenses around the underlying endoderm and the epithelial buds grow in size, while the exocrine and endocrine cells differentiate [1].

During development, the endodermal region committed to form the pancreas initially produces the transcription factor pancreatic and duodenal homeobox 1 (Pdx-1), a marker of pancreatic progenitors also produced in mature beta cells [2]. The basic helix-loop-helix factor neurogenin 3 (Neurog3) is then transiently produced in epithelial pancreatic progenitor cells prior to endocrine differentiation [3]. Neurog3 controls the expression of NeuroD, which is another member of the basic helix-loop-helix transcription factor family [4].

Pancreatic development is controlled by signals derived from tissues in contact with the endodermal region that gives rise to the pancreas [5]. Pancreatic development also depends on environmental signals such as oxygen tension $[6,7]$ and nutrients [8]. We previously showed that glucose controls beta cell development [9]. Specifically, we found that glucose favours pancreatic endocrine cell development by regulating the transition between Neurog 3 and NeuroD [9].

Typically, glucose is transported inside the cell and is phosphorylated into glucose 6-phosphate. It next enters three pathways: the glycolysis pathway to provide energy, the hexosamine biosynthetic pathway (HBP) and the pentose phosphate pathway [10]. We previously demonstrated that the positive effect of glucose on beta cell development required its metabolism through the HBP [11]. This pathway produces UDP- $N$-acetyl-glucosamine (UDP-GlcNAc), a substrate for $\mathrm{N}$ - and $\mathrm{O}$-glycosylation, as well as for $O$-GlcNAcylation, which consists of the addition of a single GlcNAc moiety to serine and threonine residues (for a review, see Bouche et al [12]). This last modification is highly dynamic and often compared with phosphorylation.

Interestingly, the pentose phosphate pathway is an alternative pathway for glucose metabolism that generates NADPH and synthesises pentose sugars [13]. Xylulose 5-phosphate, an intermediate of the pentose phosphate pathway, activates type 2A protein phosphatase (PP2A), which in turn dephosphorylates and activates transcription factor carbohydrateresponsive element binding protein (ChREBP) [14, 15].
ChREBP is a transcription factor that belongs to the basic helix-loop-helix leucine zipper family, which transactivates glucose-responsive genes such as those encoding acetylCoA carboxylase (ACCase) and liver-type pyruvate kinase (L-PK) by binding the carbohydrate-responsive element [16]. To the best of our knowledge, little information is available concerning the role of ChREBP in pancreatic cell development.

Here, we tested the possible involvement of ChREBP in pancreatic development, and the role of ChREBP as a mediator of glucose effect on beta cell differentiation. For this purpose, we modulated ChREBP activity in an in vitro model of pancreatic development and analysed beta cell differentiation.

\section{Methods}

Animals and dissection of dorsal pancreatic rudiments Pregnant Wistar rats were purchased from CERJ (Le Genest, St Isle, France). The first day post-coitum was designated embryonic day 0.5 (E0.5). Pregnant rats at 13.5 days of gestation were killed by carbon dioxide asphyxiation in compliance with the French Animal Care Committee's guidelines. Dorsal pancreatic buds from E13.5 rat embryos were dissected as previously described [17]. Pancreases from E18.5 WT or Neurog $3^{-/}$mice were dissected and used for RNA extraction.

Organ culture, PP2A inhibitor treatments and BrdU incorporation Pancreases were laid on $0.45 \mu \mathrm{m}$ filters (Millipore, St-Quentin-en-Yvelines, France) at the air-medium interface in Petri dishes containing RPMI 1640 (Lonza, Basel, Switzerland) supplemented with penicillin $(100 \mathrm{U} / \mathrm{ml})$, streptomycin $(100 \mu \mathrm{g} / \mathrm{ml})$, HEPES $(10 \mathrm{mmol} / \mathrm{l})$, non-essential amino acids (1X; Invitrogen, Cergy-Pontoise, France) and $10 \%$ heat-inactivated FCS (HyClone, Logan, UT, USA) (complete RPMI culture medium) [18]. Cultures were maintained at $37^{\circ} \mathrm{C}$ in humidified $95 \%$ air- $5 \% \mathrm{CO}_{2}$. D-Glucose, xylitol, okadaic acid, calyculin A and GlcNAc (SigmaAldrich, Lyon, France) were used at the indicated concentrations. It has to be noted that, in the medium without added glucose, about $1 \mathrm{mmol} / \mathrm{l}$ glucose is added by the serum. The medium was changed every other day. For cell proliferation assays, $10 \mu \mathrm{mol} / \mathrm{l} \mathrm{BrdU}$ (Sigma-Aldrich) was added to the medium during the last hour of culture. At the end of the indicated culture period, the pancreatic rudiments were photographed.

Pancreatic dissociation and adenoviral infection Pancreases were dissected and kept in PBS-2\% FCS, before being resuspended in $500 \mu$ l Hank's balanced salt solution (HBSS) containing collagenase $\mathrm{V}(1 \mathrm{mg} / \mathrm{ml})$ and DNase 
(20 $\mu \mathrm{g} / \mathrm{ml})$ (both from Sigma-Aldrich). The dissociation was performed at $37^{\circ} \mathrm{C}$ in a thermomixer (Eppendorf, Le Pecq, France). At the end of the dissociation, complete RPMI culture medium was added to the cell suspension which was then centrifuged for $1 \mathrm{~min}$ at $2,000 \mathrm{~g}$. The cells were washed three times and divided into aliquots in $1.5 \mathrm{ml}$ tubes $\left(5 \times 10^{4}\right.$ cells/tube $)$ in $500 \mu \mathrm{l}$ complete RPMI culture medium supplemented with ROCK inhibitor $(7 \mu \mathrm{g} / \mathrm{ml}$; Sigma-Aldrich). The tubes were centrifuged for $1 \mathrm{~min}$ at 2,000 $\mathrm{g}$ and kept open overnight in the incubator. During this period, cells reaggregated and formed clusters that were transferred on a filter and cultured for 6 further days in complete RPMI culture medium supplemented with ROCK inhibitor. For adenoviral infection, dissociated cells were cultured in $50 \mu \mathrm{l}$ RPMI 1640 with adenoviruses (multiplicity of infection of two) producing a dominant-negative ChREBP (also known as Mlxipl) into the basic region of the DNA binding domain $(\operatorname{dnChREBP})$ [19], or green fluorescent protein (GFP) as a control for $2 \mathrm{~h} 30 \mathrm{~min}$ at $37^{\circ} \mathrm{C}$. At the end of the infection period, $500 \mu \mathrm{l}$ complete RPMI medium was added, and cells were centrifuged for $1 \mathrm{~min}$ at 3,000 rpm and reaggregated as described above, before being transferred on a floating filter for 6 days.

Immunohistochemistry Tissues were fixed in $10 \%$ formalin, pre-embedded in low-gelling agarose, and embedded in paraffin. All sections ( $4 \mu \mathrm{m}$ thick) of each pancreatic explant were collected and processed for immunohistochemical analysis as previously described [20,21]. Antibodies were used in the following dilutions: mouse anti-insulin, 1/2,000; rabbit anti-insulin, 1/2,000; rabbit anti-amylase, 1/300 (all from Sigma-Aldrich); rabbit anti-proconvertase $1 / 3$ (PC1/3), 1/1,000 (gift from Dr Steiner, University of Chicago, IL, USA); mouse anti-synaptophysin, 1/10 (Dako, Trappes, France); rabbit anti-PDX1 T1/1,000 T[22]; mouse anti-GFP, 1/500 (Euromedex, Souffelweyersheim, France); mouse antiBrdU, 1/4 (Amersham Biosciences, Amersham, Buckinghamshire, UK). The fluorescent secondary antibodies used included fluorescein anti-rabbit and Texas red anti-mouse antibodies (both from Jackson ImmunoResearch, Newmarket, Suffolk, UK) and Alexa Fluor 488 anti-rabbit antibody (Invitrogen). Nuclei were stained with Hoechst $33342(0.3 \mu \mathrm{g} / \mathrm{ml}$; Invitrogen).

TUNEL experiments were performed using an in situ cell death detection kit (Roche, Neuilly-sur-Seine, France), following the manufacturer's instructions, on pancreases cultured for 7 days in the presence of glucose $10 \mathrm{mmol} / 1$ or xylitol $10 \mathrm{mmol} / 1$ alone or supplemented with okadaic acid or calyculin $\mathrm{A}$ at the indicated concentrations. Results are expressed as the percentage of apoptotic cells per total number of pancreatic cells, determined by the quantification of nuclei stained in blue with Hoechst 33342.
Quantification All sections from each pancreatic rudiment were digitised using cooled, three-charge-coupled-device cameras (Hamamatsu, Middlesex, NJ, USA) linked to a fluorescence microscope (Leitz DMRB; Leica, RueilMalmaison, France). On every image, the surface area of each staining was quantified using Image $\mathrm{J} 1.34 \mathrm{~s}$ and summed to obtain the total surface area per explant in $\mathrm{mm}^{2}$ as previously described $[9,23]$. To quantify the proliferation of early PDX1-positive pancreatic progenitors, we counted the frequency of BrdU-positive nuclei among 2,000 early PDX1-positive progenitors per rudiment. A similar analysis was performed in order to quantify the proliferation of insulin-positive cells. In order to determine the rate of cell proliferation in pancreases cultured in the presence of glucose or xylitol alone, or supplemented with okadaic acid or calyculin A, we determined the percentage of BrdU-positive cells among all pancreatic cells. At least four explants grown under each set of culture conditions were analysed. Results are expressed as means \pm SEM.

RNA extraction and real-time PCR Total RNA was extracted from pools of three pancreases using an RNeasy Microkit (Qiagen, Courtaboeuf, France) and reversetranscribed using SuperScript reagents (Invitrogen). RTPCR was performed using the 7300 Fast RT-PCR system (Applied Biosystems, Courtaboeuf, France). Oligonucleotide sequences are available upon request. Peptidylpropyl isomerase A was used as endogenous control, and E16.5 pancreas cDNA was used as calibrator sample. Data were analysed by the comparative CT method and presented as the fold change in gene expression normalised to an E16.5 calibrator that equalled a value of 1 [9]. At least three pools of explants were analysed per condition, and the results are expressed as means \pm SEM.

Statistics Results are expressed as means \pm SEM. Statistical significance was determined using the Student's $t$ test when only two sets of data were compared. For larger analyses, a non-parametric Kurskal and Wallis test was performed, followed by a Mann-Whitney $U$ test.

\section{Results}

Expression of the transcription factor ChREBP during pancreatic development We first analysed the ChREBP expression pattern during pancreatic development. ChREBP mRNA was detected in vivo in the pancreas as early as E13.5, its expression gradually increasing at E15.5, E16.5 and E18.5, following a pattern that resembled the one found for Ins and amylase mRNA (Fig. 1a-c). ChREBP levels decreased sharply in pancreases from Neurog3-deficient mice, indicating that its expression was highly enriched in 


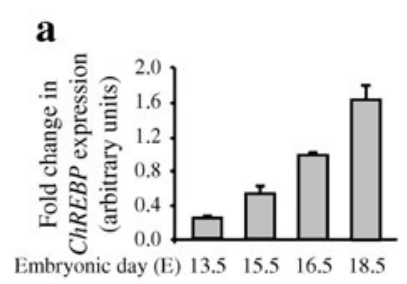

b

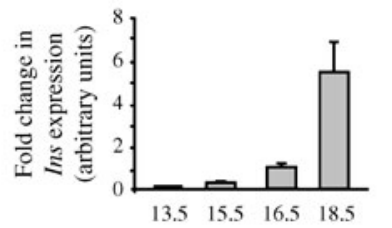

c

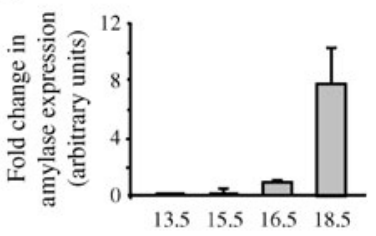

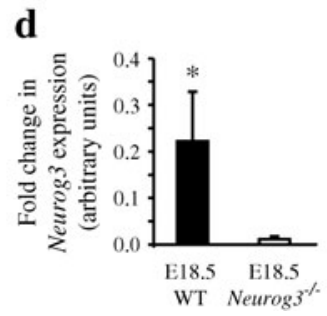

e

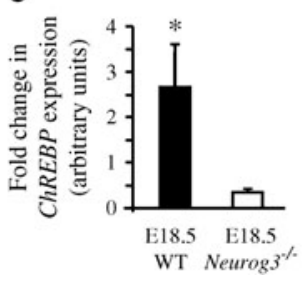

f

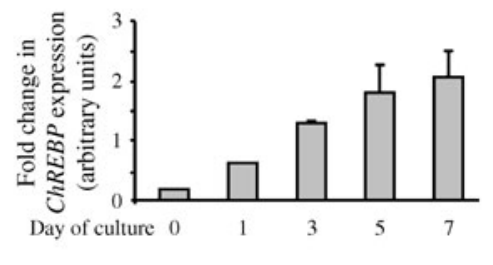

Fig. 1 Levels of the transcription factor ChREBP during pancreatic development. RT-PCR quantification of ChREBP (a), Ins (b) and amylase (c) mRNA in the pancreas at various stages of embryonic development (E13.5, E15.5, E16.5 and E18.5). (d,e) RT-PCR quantification of Neurog3 and ChREBP mRNA in E18.5 pancreases of wild

the endocrine pathway (Fig. 1d). In an in vitro model of pancreatic development in which acinar and endocrine cells developed from E13.5 pancreases [18], ChREBP expression level increased as cell differentiation occurred (Fig. 1f).

Xylitol and glucose treatments induce the expression of ACCase (also known as Acaca) and L-PK (also known as Pklr), two direct targets of ChREBP We first tested the effect of xylitol and glucose on the expression of ACCase and $L-P K$ mRNA, two direct targets of ChREBP. Xylulose 5-phosphate, an intermediate of the non-oxidative branch of the pentose phosphate pathway, activates PP2A, which will dephosphorylate and activate ChREBP [24]. Treatment with either glucose or xylitol, a precursor of xylulose 5-phosphate, can thus activate ChREBP [25]. In E13.5 rat pancreases in culture, both xylitol and glucose induced ACCase and L-PK mRNA levels (Fig. 2). This induction occurred in a glucose dose-dependent manner (see electronic supplementary material [ESM] Fig. 1).

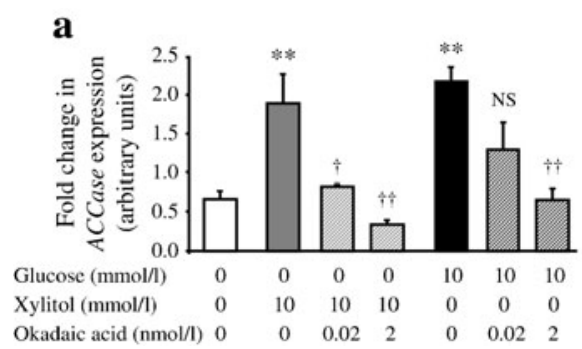

Fig. 2 Effect of glucose, xylitol or okadaic acid treatment on the expression of $A C C$ ase and $L-P K$, two ChREBP targets. (a,b) Quantification by RT-PCR of ACCase (a) and $L-P K$ (b) mRNAs after 7 days of culture of E13.5 rat pancreases in the presence or absence of xylitol $(10 \mathrm{mmol} / \mathrm{l})$, type or Neurog $3^{-/}$mice. (f) RT-PCR quantification of ChREBP mRNA in E13.5 rat pancreases before (day 0) and after 1, 3, 5 and 7 days of culture. All values are means \pm SEM of minimum three independent experiments. ${ }^{*} p<0.05$

Treatment with okadaic acid, a PP2A inhibitor, reversed xylitol-induced activation of ACCase and $L-P K$ expression, an effect that was stronger at $2 \mathrm{nmol} / \mathrm{l}$ than at $0.02 \mathrm{nmol} / \mathrm{l}$ (Fig. 2). Such an effect was also observed with calyculin A, another PP2A inhibitor (data not shown). Interestingly, okadaic acid treatment also reversed glucose-induced activation of $A C C$ ase and $L-P K$ expression, but the effect was observed only with $2 \mathrm{nmol} / \mathrm{l}$ okadaic acid (Fig. 2).

Glucose and xylitol treatments activate beta cell development As we observed that the expression of ChREBP targets was induced in response to either glucose or xylitol, we analysed their effects on pancreatic development. To this end, E13.5 rat pancreases were cultured for 7 days in medium without added glucose (control medium) or with glucose (10 mmol/l) or xylitol (3 and $10 \mathrm{mmol} / \mathrm{l})$. Xylitol treatment modified neither pancreatic morphology nor the size of the tissue as quantified following Hoechst staining, nor acinar cell development measured after amylase staining (Fig. 3).

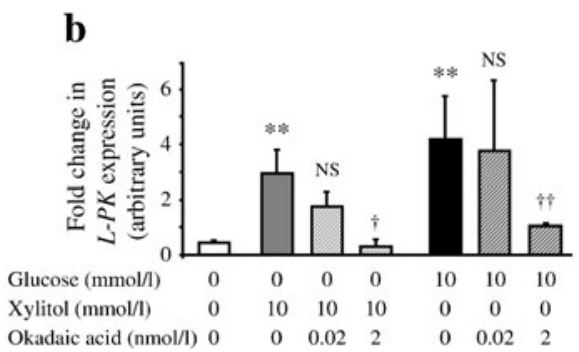

glucose $(10 \mathrm{mmol} / \mathrm{l})$ and okadaic acid (2 or $0.02 \mathrm{nmol} / \mathrm{l})$. Values are means \pm SEM of three independent experiments. $* * p<0.01$ compared with pancreases cultured without glucose. ${ }^{\dagger} p<0.05$ and ${ }^{\dagger \dagger} p<0.01$ when compared with pancreases cultured without okadaic acid 
However, xylitol increased the development of insulinproducing beta cells, as was the case for glucose, as measured after insulin immunostaining (Fig. 3b-e). This increase in insulin level was observed at both 3 and $10 \mathrm{mmol} / \mathrm{l}$ xylitol, and $10 \mathrm{mmol} / \mathrm{l}$ xylitol was chosen for subsequent experiments.

Insulin-positive cells that developed in the presence of xylitol produced beta cell markers such as the transcription factor PDX1, an insulin gene transactivator, the pro-convertase $1 / 3$, implicated in proinsulin processing, and synaptophysin, a protein present on the endocrine pancreatic secretory granule membrane (ESM Fig. 2). Such results support the fact that insulin-positive cells that developed in the presence of xylitol are indeed beta cells.

Glucose and xylitol treatments do not affect pancreatic cell proliferation Our data indicate that xylitol treatment increased beta cell development. Pancreatic endocrine cells derive from early proliferating pancreatic progenitors producing the transcription factor PDX1 [26, 27]. We first asked whether xylitol increased beta cell mass by acting on the proliferation of either PDX1-positive pancreatic progenitors or mature beta cells. E13.5 pancreases were cultured for 1 or 7 days, BrdU being added during the last hour of culture. In control conditions, $28.45 \pm 0.57 \%$ of PDX1positive cells and $2.39 \pm 0.35 \%$ of insulin-positive cells incorporated BrdU after 1 and 7 days of culture, respectively (ESM Fig. 3). Thus, neither xylitol nor glucose treatment modified rates of proliferation.

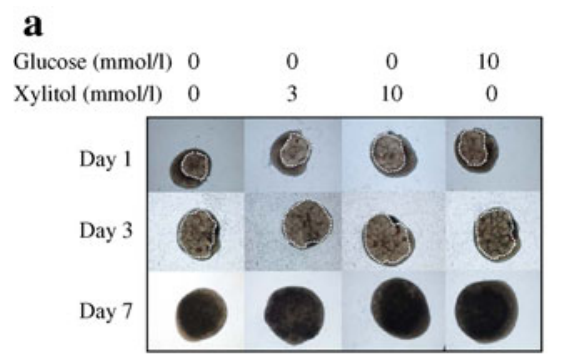

b

c

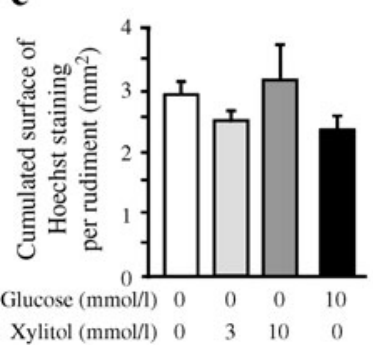

d

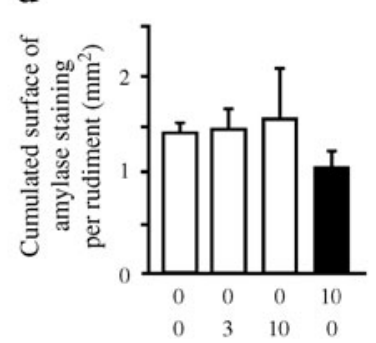

Glucose and xylitol treatments promote beta cell differentiation by activating the transition between Neurog3 and NeuroD During development, PDX1-positive pancreatic progenitors give rise to NEUROG3-positive endocrine progenitors that will differentiate into beta cells [3, 28]. In control pancreatic explants, as previously observed [9], Neurog3 mRNA levels measured by RT-PCR increased after 1 day of culture, peaked at day 3 and decreased thereafter (Fig. 4a). Xylitol treatment did not modify the pattern of Neurog3 expression (Fig. 4a). On the other hand, when compared with control conditions, xylitol treatment increased the level of NeuroD, a target of NEUROG3 necessary for proper beta cell development (Fig. 4b) [29]. As expected based on the immunohistochemical analysis performed on day 7 , xylitol treatment increased the INS gene expression pattern (Fig. 4c) without modifying amylase gene expression (Fig. 4d). When glucose was used instead of xylitol, similar effects were observed on endocrine (Neurog3, NeuroD, Ins) and acinar (amylase) cell development. Collectively, these results indicate that xylitol, like glucose, acts specifically on endocrine cell development, by controlling the transition between Neurog3 and NeuroD.

The effect of glucose and xylitol treatments on beta cell development depends on ChREBP activation The data described above indicate that, during pancreatic development, xylitol induces both ChREBP activity and beta cell differentiation. To determine whether the effect of xylitol on beta

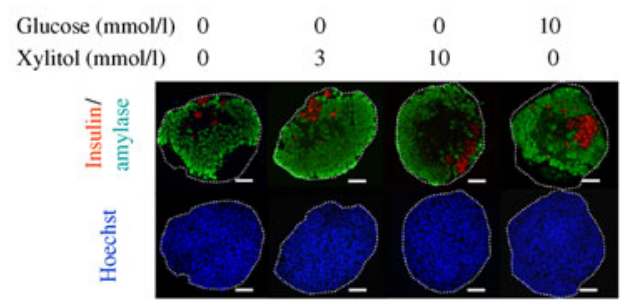

e

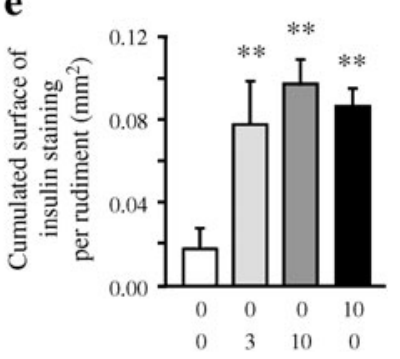

Fig. 3 Glucose and xylitol activate the development of insulinpositive cells. (a) E13.5 rat pancreases were cultured for 7 days in the presence or absence of xylitol (3 or $10 \mathrm{mmol} / \mathrm{l}$ ) or glucose (10 mmol/l). Representative images after 1,3 and 7 days in culture are shown. Pancreatic epithelium is circled in white. (b) Immunohistological analysis of pancreases after 7 days of culture in the absence or in presence of xylitol ( 3 or $10 \mathrm{mmol} / \mathrm{l}$ ) or in the presence of glucose $(10 \mathrm{mmol} / \mathrm{l})$. Insulin was revealed in red and amylase in green. Nuclei are depicted in blue by Hoechst staining. The pancreatic bud is outlined in white. Scale bar: $100 \mu \mathrm{m}$. (c-e) Quantification of the absolute surface areas occupied by Hoechst-, amylase- and insulin-positive cells after 7 days of culture in the absence or presence of xylitol or glucose 


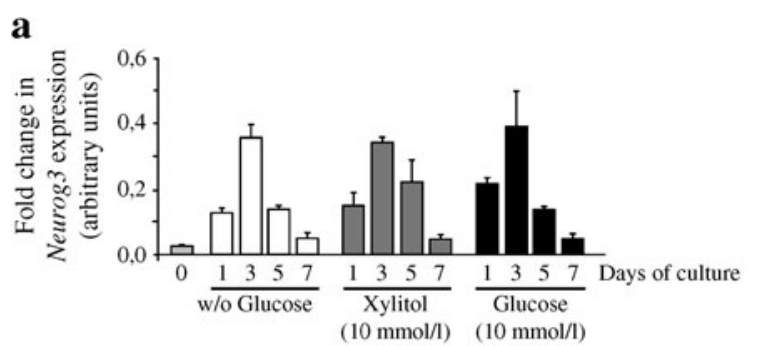

b

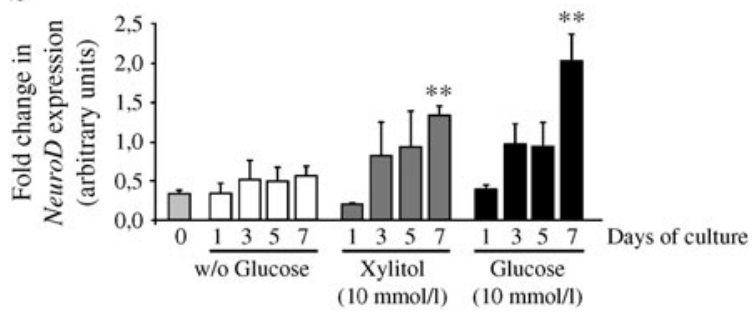

c

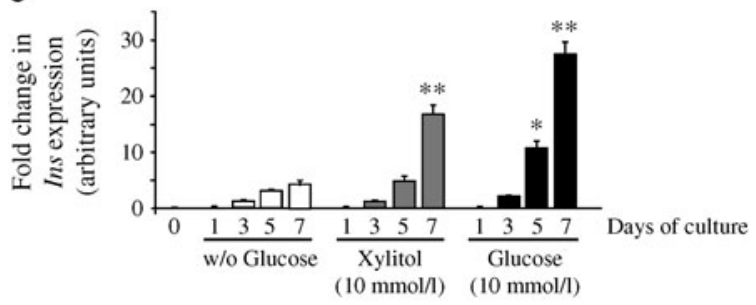

d

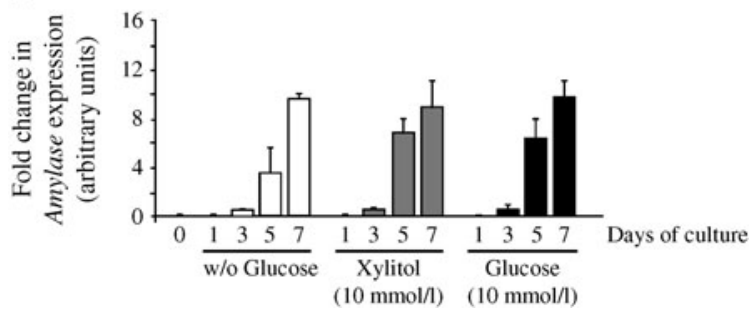

Fig. 4 Glucose and xylitol treatments promote beta cell differentiation by activating the transition between NEUROG3 and NeuroD. RT-PCR quantification of Neurog3, NeuroD, Ins and amylase mRNA in E13.5 pancreases before (day 0 ) and after 1, 3, 5 and 7 days of culture in the presence or absence of xylitol $(10 \mathrm{mmol} / \mathrm{l})$ or glucose $(10 \mathrm{mmol} / \mathrm{l})$. Comparisons were performed at each time point with pancreases cultured without glucose. Values are means \pm SEM of a minimum of three independent experiments. ${ }^{*} p<0.05 ;{ }^{* *} p<0.01$

cell differentiation was dependent on ChREBP activation, we cultured E13.5 pancreases in medium supplemented or not supplemented with xylitol or glucose, in the presence or absence of okadaic acid. Okadaic acid treatment $(0.02$ or $2 \mathrm{nmol} / \mathrm{l}$ ) did not modify pancreatic shape and growth (Fig. 5a,b). After 7 days of culture, okadaic acid treatment did not modify acinar cell development quantified by amylase immunostaining and by RT-PCR (Fig. 5a-d). On the other hand, the increase in beta cell development observed with glucose or xylitol treatment was abolished by okadaic acid treatment both at 0.02 and $2 \mathrm{nmol} / \mathrm{l}$, as quantified by insulin immunostaining and by RT-PCR (Fig. 5a-f). A similar effect was observed with calyculin A (data not shown). Importantly, PP2A inhibitors modulate neither cell proliferation nor apoptosis (ESM Fig. 4). An alteration of these variables can therefore not explain the observed decreased in beta cell mass.

To further demonstrate the role of CHREBP in beta cell development, we infected rat embryonic pancreases with an adenovirus producing dnChREBP [19]. For efficient infection, we dissociated E13.5 rat pancreatic cells, infected them with adenoviruses and next reassociated the cells before culture. We first verified that, in this assay, glucose exerted a positive effect on beta cell differentiation, as previously shown with undissociated pancreas [9]. This was indeed the case as glucose induced a 2.56-fold increase in beta cell development without modifying acinar cell development (ESM Fig. 5).

In order to test the efficiency of gene transfer in this model, dissociated cells were infected with an adenovirus producing GFP. Cells were reaggregated, cultured for 2 days, fixed and stained using an anti-GFP antibody. Almost all cells produced GFP, demonstrating that infection was highly efficient (data not shown). We next compared beta and acinar cell development in pancreases that were or were not infected with a GFP or a dnChREBP adenovirus. After 7 days of culture post-infection, the relative mass of amylase-positive cells was similar in all three conditions (Fig. 6a,b). On the other hand, although infection with an adenovirus producing GFP did not modify beta cell development, the relative number of insulin-positive cells was reduced in pancreases infected with an adenovirus producing dnChREBP (Fig. 6a-c). Of note, the percentage of insulin-positive cells that developed in the presence of the adenovirus producing dnChREBP was similar to the one obtained in reaggregated pancreases culture for 7 days in the absence of added glucose (compare Fig. 6c and ESM Fig. 3B).

The effect of GlcNAc treatment on beta cell development depends on ChREBP activation We previously demonstrated that the effect of glucose on beta cell development was dependent on its metabolism through the HBP [11]. Specifically, in the absence of added glucose, GlcNAc, a known substrate of the HBP, induced beta cell differentiation from embryonic pancreases and thus reproduced the effects of glucose. We therefore asked whether the effect of GlcNAc treatment on beta cell development was also dependent on ChREBP activation. Dissociated pancreases were infected with an adenovirus producing GFP or dnChREBP, and cultured for 7 days in the absence of glucose but with the addition of GlcNAc $50 \mathrm{mmol} / \mathrm{l}$. We first verified that, in this assay, GlcNAc exerted a positive effect on beta cell differentiation, as previously demonstrated for undissociated pancreases [11]. This was indeed the 
a

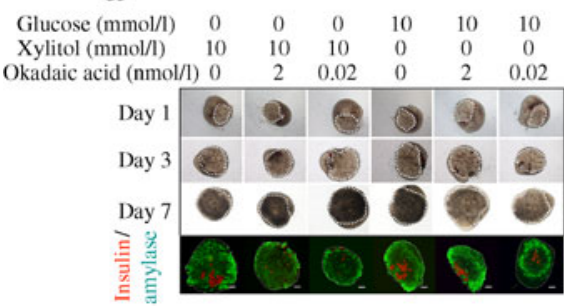

c

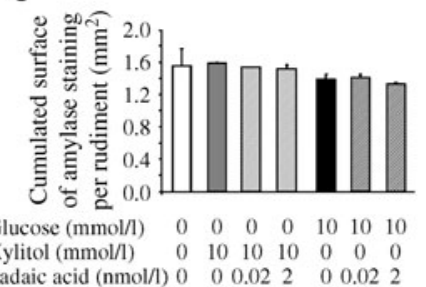

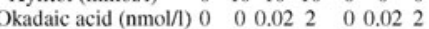

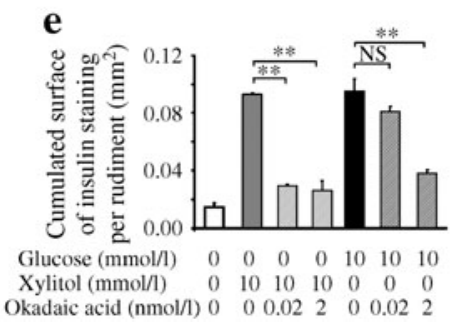

Fig. 5 Effect of okadaic acid treatment on the expression of ACCase and $L-P K$. (a) Representative images of pancreases cultured for 1, 3 and 7 days indicating that okadaic acid treatment did not modify pancreatic shape. Pancreatic epithelium is circled in white. After 7 days of culture, immunohistochemistry experiments were performed on the pancreatic buds. Insulin was revealed in red and amylase in green. Scale bar: $100 \mu \mathrm{m}$. (b) Quantification of the absolute surface area occupied by Hoechst staining after 7 days of culture of 13.5 rat pancreases in the presence or absence of xylitol $(10 \mathrm{mmol} / \mathrm{l})$, glucose $(10 \mathrm{mmol} / \mathrm{l})$ or okadaic acid (2 or $0.02 \mathrm{nmol} / \mathrm{l})$. (c,e) Quantification of

case as GlcNAc induced beta cell differentiation to the same extent as glucose (Fig. 6c; compare the black columns). Infection with the adenovirus producing GFP did not modify the positive effect of GlcNAc on beta cell differentiation (Fig. 6a,c), whereas when pancreases were infected with the adenovirus producing dnChREBP, beta cell differentiation was reduced (Fig. 6a,c). Again, none of the conditions modified acinar cell differentiation (Fig. 6a,b). These results demonstrated that the positive effect of glucose and GlcNAc on beta cell differentiation require active ChREBP.

\section{Discussion}

Pancreatic beta cell development is a multistep process. Information is now available on the signals that regulate early steps of the process, i.e. the development of PDX1-positive pancreatic progenitors from definitive endoderm [30-32]. On the other hand, less is known about signals controlling beta cell b

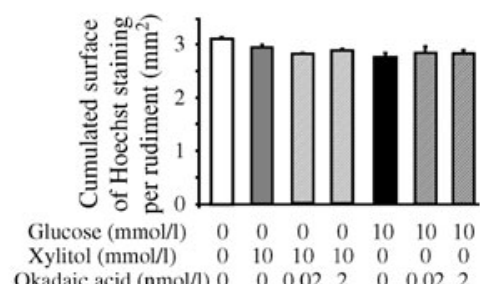

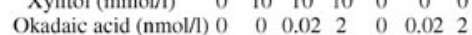

d

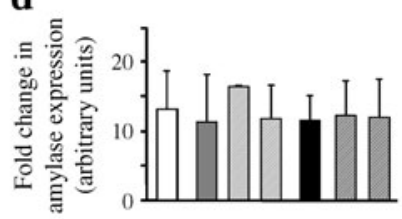

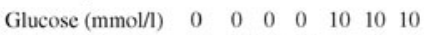

$\begin{array}{llllllll}\text { Xylitol }(\mathrm{mmol} / \mathrm{l}) & 0 & 10 & 10 & 10 & 0 & 0 & 0\end{array}$

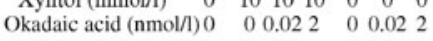

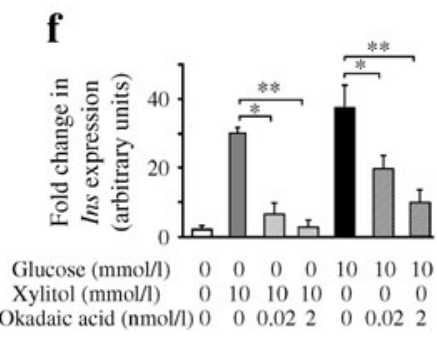

the absolute surface area occupied by amylase (c) and insulin staining (e) after 7 days of culture of 13.5 rat pancreases in the presence or absence of xylitol $(10 \mathrm{mmol} / \mathrm{l})$, glucose $(10 \mathrm{mmol} / \mathrm{l})$ or okadaic acid (2 or $0.02 \mathrm{nmol} / \mathrm{l})$. (d,f) Quantification by RT-PCR of amylase (d) and Ins (f) mRNA after 7 days of culture of 13.5 rat pancreases in the presence or in the absence of xylitol $(10 \mathrm{mmol} / \mathrm{l})$, glucose $(10 \mathrm{mmol} / \mathrm{l})$ and okadaic acid ( 2 or $0.02 \mathrm{nmol} / \mathrm{l})$. Values are means \pm SEM of three independent experiments. ${ }^{*} p<0.05,{ }^{*} p<0.01$ and NS compared with pancreases cultured in the presence of glucose

differentiation from PDX1-positive pancreatic progenitors. This step in development can be further divided into three consecutive steps: (1) the proliferation of PDX1-positive pancreatic progenitors; (2) their differentiation into acinar tissue or into NEUROG3-producing endocrine progenitors; and (3) the differentiation of NEUROG3-producing endocrine progenitors into insulin-producing beta cells [33]. Here, by using activators and inhibitors of the pentose phosphate shunt, we demonstrated that this pathway modulated neither the proliferation of PDX1-positive pancreatic progenitors, nor acinar cell differentiation, nor the formation of NEUROG3producing endocrine progenitors. On the other hand, we demonstrated that the positive effect of glucose and xylitol on pancreatic beta cell differentiation depended on the transcription factor ChREBP and occurred in NEUROG3producing endocrine progenitors.

In this study, we used an in vitro bioassay that recapitulates the major steps occurring during beta cell development from PDX1-positive fetal pancreatic progenitor cells. 
a

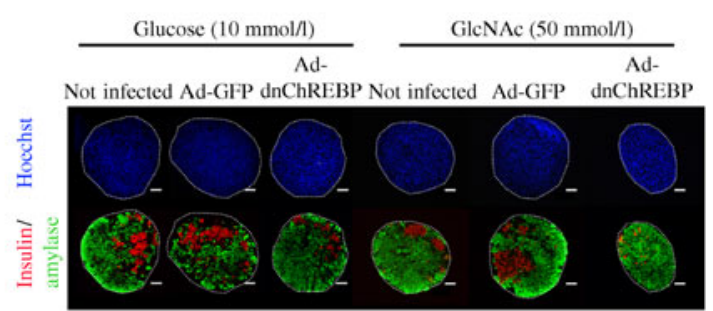

b

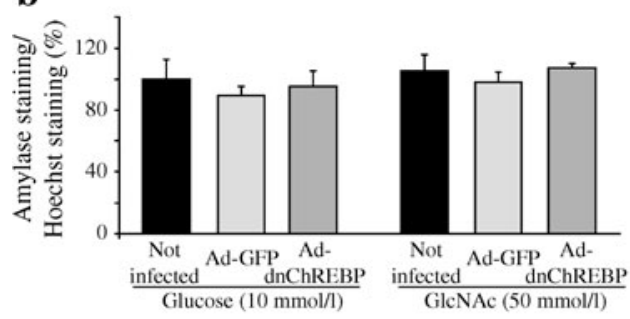

c

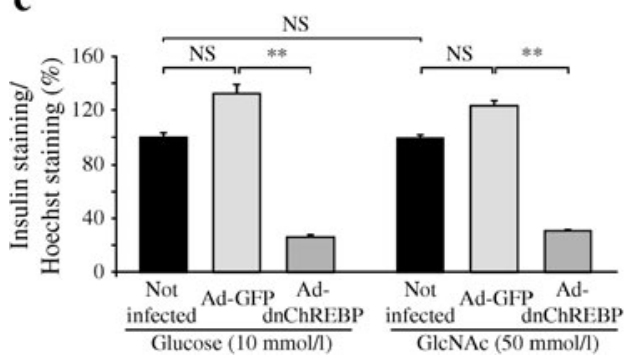

Fig. 6 Ad-dnChREBP blocks the effect of glucose and GlcNAc on beta cell development. E13.5 rat pancreases were dissociated, infected or not infected with Ad-GFP or Ad-dnChREBP, reaggregated and cultured in the presence of glucose $(10 \mathrm{mmol} / \mathrm{l})$ or in the presence of GlcNAc $(50 \mathrm{mmol} / \mathrm{l})$. (a) Immunohistological analysis of pancreases after 7 days of culture. Insulin was revealed in red and amylase in green. Nuclei were stained blue using a Hoechst dye. Scale bar: $100 \mu \mathrm{m}$. (b) Quantification of the relative surface area occupied by amylase-positive cells after 7 days of culture. Values were normalised to the condition 'not infected and culture in presence of glucose $10 \mathrm{mmol} / \mathrm{l}$ '. (c) Quantification of the relative surface area occupied by insulin-positive cells after 7 days of culture. Values were normalised to the condition "not infected and culture in presence of glucose $10 \mathrm{mmol} / 1 .{ }^{* *} p<0.01$

In this model, PDX1-positive pancreatic progenitors first proliferate and next differentiate into endocrine or acinar tissue. We previously validated and used this model to define factors and conditions that regulate specific steps in beta cell development. Specifically, with this assay, we previously demonstrated that fibroblast growth factor 10 was an activator of the proliferation of PDX1-positive pancreatic progenitors [18]. Here, we found that xylitol did not regulate cell proliferation during pancreatic development, as previously shown for glucose [9]. We also previously used this model of in vitro pancreatic development to define signals and conditions that modulate the differentiation of PDX1-positive pancreatic progenitors into NEUROG3-positive endocrine progenitors. We demonstrated that small molecules such as histone deacetylase inhibitors [23], branched amino acids [34] and oxygen tension
[7] regulate the development of NEUROG3-positive endocrine progenitors from PDX1-positive pancreatic progenitors. Recently, using the same assay, we demonstrated that glucose regulates the next step in beta cell development, i.e. the differentiation of beta cells from NEUROG3positive endocrine progenitors, and that glucose metabolism was implicated in this regulation at least in part through activation of the HBP $[9,11]$.

In the present study, we demonstrated that the transcription factor ChREBP regulates beta cell differentiation. ChREBP regulates gene transcription in response to glucose (for a review, see [24]). Specifically, the pentose phosphate pathway, and particularly xylulose 5-phosphate, selectively activates PP2A, which in turn dephosphorylates the transcription factor ChREBP [14]. This allows ChREBP translocation into the nucleus and activation of ChREBP targets, such as the glycolytic gene $L-P K$ [35] or the lipogenic genes ACCase and Fas (which encodes fatty acid synthase) [36]. ChREBP production is most abundant in liver, and is small in kidney and white and brown adipose tissue [16]. In adult islets, ChREBP controls the expression of a number of genes such as $L-P K$ [37], ACCase [38], Fas [39], thioredoxin-interacting protein [40] and aryl hydrocarbon receptor nuclear translocator [41]. Interestingly, recent data suggest that ChREBP can also be activated by glucose 6-phosphate [42] and by the HBP [43, 44], placing ChREBP at the crossroads of all glucose metabolic pathways.

Little information has been available on the role of ChREBP during pancreatic development. Different arguments derived from the present study indicate that ChREBP is important for proper beta cell differentiation. First, as described in this study, ChREBP is expressed in the pancreas during development [45]. Second, during prenatal life, ChREBP is highly enriched in the endocrine pathway, as demonstrated by its sharp decrease in pancreases from Neurog3-deficient mice that lack endocrine cells. ChREBP can thus be added to the list of genes whose expression is enriched in pancreatic endocrine cells [46]. Third, in the embryonic pancreas, xylitol, a precursor of xylulose 5phosphate and an intermediary molecule of the pentose phosphate pathway, activates the expression of ACCase and $L-P K$, two direct targets of ChREBP, demonstrating that this pathway is functional during pancreatic development. Fourth, xylitol activates beta cell differentiation without affecting acinar cell development. This fits well with the fact that ChREBP is highly enriched in cells of the endocrine pathway. In addition, okadaic acid and calyculin A, two inhibitors of the serine/threonine PP2A, which inhibit ChREBP activity [47, 48], suppress the effects of xylitol on beta cell development. Finally, the production of dnChREBP suppresses the effects of both glucose and GlcNAc, a substrate of the HBP, on beta cell development. Taken together, such data demonstrate that ChREBP tightly regulates beta cell development.

We have recently demonstrated that the HBP mediates, at least in part, the effect of glucose on beta cell differentiation 
[11]. Specifically, we had proposed that the HBP controlled an $O$-GlcNAcylated factor necessary for proper beta cell differentiation [11]. It is now established that ChREBP is $O$-GlcNAcylated [43, 44]. We propose that glucose controls beta cell differentiation, by promoting ChREBP activity, first by allowing its dephosphorylation, and second through the HBP, which would regulate ChREBP $O$-GlcNAcylation. These two steps, controlled by glucose, would permit efficient beta cell differentiation. One element supporting this hypothesis is the fact that, in pancreases infected with an AddnChREBP, the positive effect of GlcNAc on beta cell differentiation is lost (Fig. 6). Therefore, the effect of glucose on beta cell development, via its metabolism through the HBP, requires an active ChREBP. ChREBP is thus at the crossroads of the different glucose metabolic pathways regulating beta cell differentiation from pancreatic progenitors.

The phenotype of mice deficient in ChREBP was recently analysed [16]. Such mice were glucose-intolerant, but their pancreatic phenotype was not described. In light of our data, it would be interesting to study pancreatic beta cell development in such mice. It will also be interesting to determine whether glucose, through ChREBP activation, controls human beta cell differentiation. Such information would be important in protocols aiming at generating human beta cells from stem cells.

Acknowledgements We would like to thank H.C. Towle (Department of Biochemistry, Molecular Biology and Biophysics, Minneapolis, Minnesota) for the Ad-dnChREBP and S. Fabrega (core facility: Viral Vectors and Gene Transfer, University Paris Descartes, Institut Fédératif de Recherche Necker Enfants Malades IFR94, Paris, France) for the production of GFP adenovirus and for the virus amplification.

Funding This work was supported by the 6th European Union Framework Program (Beta-Cell Therapy Integrated Project) (to RS).

Duality of interest The authors declare that there is no duality of interest associated with this manuscript.

Author's contribution AS and KF performed experiments, analysed the data and contributed to revision of the article. PR and GS provided expertise and reagents, and contributed to the acquisition of data and revision of the article. RS analysed the data and wrote the manuscript. GG conceived and designed the experiments, performed experiments, analysed the data and wrote the manuscript. All authors approved the final version of the article.

Open Access This article is distributed under the terms of the Creative Commons Attribution License which permits any use, distribution, and reproduction in any medium, provided the original author(s) and the source are credited.

\section{References}

1. Pictet RL, Clark WR, Williams RH, Rutter WJ (1972) An ultrastructural analysis of the developing embryonic pancreas. Dev Biol 29:436-467
2. Ohlsson H, Karlsson K, Edlund T (1993) IPF1, a homeodomaincontaining transactivator of the insulin gene. EMBO J 12:42514259

3. Gradwohl G, Dierich A, LeMeur M, Guillemot F (2000) Neurogenin3 is required for the development of the four endocrine cell lineages of the pancreas. Proc Natl Acad Sci U S A 97:1607-1611

4. Huang HP, Liu M, El-Hodiri HM, Chu K, Jamrich M, Tsai MJ (2000) Regulation of the pancreatic islet-specific gene BETA2 (neuroD) by neurogenin 3. Mol Cell Biol 20:3292-3307

5. Oliver-Krasinski JM, Stoffers DA (2008) On the origin of the beta cell. Genes Dev 22:1998-2021

6. Fraker CA, Alvarez S, Papadopoulos P et al (2007) Enhanced oxygenation promotes beta-cell differentiation in vitro. Stem Cells 25:3155-3164

7. Heinis M, Simon MT, Ilc K et al (2010) Oxygen tension regulates pancreatic beta-cell differentiation through hypoxia-inducible factor 1alpha. Diabetes 59:662-669

8. Hill DJ (2011) Nutritional programming of pancreatic beta-cell plasticity. World J Diabetes 2:119-126

9. Guillemain G, Filhoulaud G, Da Silva-Xavier G, Rutter GA, Scharfmann R (2007) Glucose is necessary for embryonic pancreatic endocrine cell differentiation. J Biol Chem 282:15228-15237

10. Girard J, Ferre P, Foufelle F (1997) Mechanisms by which carbohydrates regulate expression of genes for glycolytic and lipogenic enzymes. Annu Rev Nutr 17:325-352

11. Filhoulaud G, Guillemain G, Scharfmann R (2009) The hexosamine biosynthesis pathway is essential for pancreatic beta cell development. J Biol Chem 284:24583-24594

12. Bouche C, Serdy S, Kahn CR, Goldfine AB (2004) The cellular fate of glucose and its relevance in type 2 diabetes. Endocr Rev 25:807-830

13. McIntyre LM, Thorburn DR, Bubb WA, Kuchel PW (1989) Comparison of computer simulations of the F-type and L-type nonoxidative hexose monophosphate shunts with 31P-NMR experimental data from human erythrocytes. Eur J Biochem 180:399420

14. Kabashima T, Kawaguchi T, Wadzinski BE, Uyeda K (2003) Xylulose 5-phosphate mediates glucose-induced lipogenesis by xylulose 5-phosphate-activated protein phosphatase in rat liver. Proc Natl Acad Sci U S A 100:5107-5112

15. Nishimura M, Fedorov S, Uyeda K (1994) Glucose-stimulated synthesis of fructose 2,6-bisphosphate in rat liver. Dephosphorylation of fructose 6-phosphate, 2-kinase:fructose 2,6-bisphosphatase and activation by a sugar phosphate. J Biol Chem 269:2610026106

16. Iizuka K, Bruick RK, Liang G, Horton JD, Uyeda K (2004) Deficiency of carbohydrate response element-binding protein (ChREBP) reduces lipogenesis as well as glycolysis. Proc Natl Acad Sci U S A 101:7281-7286

17. Miralles F, Serup P, Cluzeaud F, Vandewalle A, Czernichow P, Scharfmann R (1999) Characterization of beta cells developed in vitro from rat embryonic pancreatic epithelium. Dev Dyn 214:116126

18. Attali M, Stetsyuk V, Basmaciogullari A et al (2007) Control of beta-cell differentiation by the pancreatic mesenchyme. Diabetes $56: 1248-1258$

19. Tsatsos NG, Davies MN, O'Callaghan BL, Towle HC (2008) Identification and function of phosphorylation in the glucoseregulated transcription factor ChREBP. Biochem J 411:261-270

20. Duvillie B, Attali M, Bounacer A, Ravassard P, Basmaciogullari A, Scharfmann R (2006) The mesenchyme controls the timing of pancreatic beta-cell differentiation. Diabetes 55:582-589

21. Miralles F, Czernichow P, Scharfmann R (1998) Follistatin regulates the relative proportions of endocrine versus exocrine tissue during pancreatic development. Development 125:10171024 
22. Duvillie B, Attali M, Aiello V, Quemeneur E, Scharfmann R (2003) Label-retaining cells in the rat pancreas: location and differentiation potential in vitro. Diabetes 52:2035-2042

23. Haumaitre C, Lenoir O, Scharfmann R (2008) Histone deacetylase inhibitors modify pancreatic cell fate determination and amplify endocrine progenitors. Mol Cell Biol 28:6373-6383

24. Iizuka K, Horikawa Y (2008) ChREBP: a glucose-activated transcription factor involved in the development of metabolic syndrome. Endocr J 55:617-624

25. Amo K, Arai H, Uebanso T et al (2011) Effects of xylitol on metabolic parameters and visceral fat accumulation. J Clin Biochem Nutr 49:1-7

26. Ahlgren U, Jonsson J, Edlund H (1996) The morphogenesis of the pancreatic mesenchyme is uncoupled from that of the pancreatic epithelium in IPF1/PDX1-deficient mice. Development 122:14091416

27. Jonsson J, Carlsson L, Edlund T, Edlund H (1994) Insulinpromoter-factor 1 is required for pancreas development in mice. Nature 371:606-609

28. Gu G, Dubauskaite J, Melton DA (2002) Direct evidence for the pancreatic lineage: NGN3+ cells are islet progenitors and are distinct from duct progenitors. Development 129:2447-2457

29. Naya FJ, Huang HP, Qiu Y et al (1997) Diabetes, defective pancreatic morphogenesis, and abnormal enteroendocrine differentiation in BETA2/neuroD-deficient mice. Genes Dev 11:2323-2334

30. D'Amour KA, Bang AG, Eliazer S et al (2006) Production of pancreatic hormone-expressing endocrine cells from human embryonic stem cells. Nat Biotechnol 24:1392-1401

31. Kroon E, Martinson LA, Kadoya K et al (2008) Pancreatic endoderm derived from human embryonic stem cells generates glucoseresponsive insulin-secreting cells in vivo. Nat Biotechnol 26:443452

32. Chen S, Borowiak M, Fox JL et al (2009) A small molecule that directs differentiation of human ESCs into the pancreatic lineage. Nat Chem Biol 5:258-265

33. Pan FC, Wright C (2011) Pancreas organogenesis: from bud to plexus to gland. Dev Dyn 240:530-565

34. Rachdi L, Aiello V, Duvillie B, Scharfmann R (2011) L-Leucine alters pancreatic beta-cell differentiation and function via the mTor signaling pathway. Diabetes 61:409-417

35. Yamashita H, Takenoshita M, Sakurai M et al (2001) A glucoseresponsive transcription factor that regulates carbohydrate metabolism in the liver. Proc Natl Acad Sci U S A 98:9116-9121

36. Dentin R, Pegorier JP, Benhamed F et al (2004) Hepatic glucokinase is required for the synergistic action of ChREBP and SREBP-
$1 \mathrm{c}$ on glycolytic and lipogenic gene expression. J Biol Chem 279:20314-20326

37. Wang H, Wollheim CB (2002) ChREBP rather than USF2 regulates glucose stimulation of endogenous L-pyruvate kinase expression in insulin-secreting cells. J Biol Chem 277:32746-32752

38. Andreolas C, da Silva XG, Diraison F et al (2002) Stimulation of acetyl-CoA carboxylase gene expression by glucose requires insulin release and sterol regulatory element binding protein $1 \mathrm{c}$ in pancreatic MIN6 beta-cells. Diabetes 51:2536-2545

39. da Silva XG, Rutter GA, Diraison F, Andreolas C, Leclerc I (2006) ChREBP binding to fatty acid synthase and L-type pyruvate kinase genes is stimulated by glucose in pancreatic beta-cells. J Lipid Res 47:2482-2491

40. Cha-Molstad H, Saxena G, Chen J, Shalev A (2009) Glucosestimulated expression of Txnip is mediated by carbohydrate response element-binding protein, p300, and histone $\mathrm{H} 4$ acetylation in pancreatic beta cells. J Biol Chem 284:16898-16905

41. Noordeen NA, Khera TK, Sun G et al (2009) Carbohydrateresponsive element-binding protein (ChREBP) is a negative regulator of ARNT/HIF-1beta gene expression in pancreatic islet betacells. Diabetes 59:153-160

42. Dentin R, Tomas-Cobos L, Foufelle F et al (2012) Glucose 6phosphate, rather than xylulose 5-phosphate, is required for the activation of ChREBP in response to glucose in liver. J Hepatol 56:199-209

43. Guinez C, Filhoulaud G, Rayah-Benhamed F et al (2011) OGlcNAcylation increases ChREBP protein content and transcriptional activity in the liver. Diabetes 60:1399-1413

44. Sakiyama H, Fujiwara N, Noguchi T et al (2010) The role of Olinked GlcNAc modification on the glucose response of ChREBP. Biochem Biophys Res Commun 402:784-789

45. Gao N, Le Lay J, Qin W et al (2010) Foxa1 and Foxa2 maintain the metabolic and secretory features of the mature beta-cell. Mol Endocrinol 24:1594-1604

46. Martens GA, Jiang L, Hellemans KH et al (2011) Clusters of conserved beta cell marker genes for assessment of beta cell phenotype. PLoS One 6:e24134

47. Garcia L, Garcia F, Llorens F, Unzeta M, Itarte E, Gomez N (2002) PP1/PP2A phosphatases inhibitors okadaic acid and calyculin A block ERK5 activation by growth factors and oxidative stress. FEBS Lett 523:90-94

48. Favre B, Turowski P, Hemmings BA (1997) Differential inhibition and posttranslational modification of protein phosphatase 1 and $2 \mathrm{~A}$ in MCF7 cells treated with calyculin-A, okadaic acid, and tautomycin. J Biol Chem 272:13856-13863 